and Company, EMD Merck Serono, Genentech/Roche, Gilead Sciences, Inc., GSK, Novartis, RPharm, Sanofi Genzyme

DOI: 10.1136/annrheumdis-2020-eular.2059

\section{SAT0152 1 EFFICACY OF BARICITINIB IN PATIENTS WITH MODERATE-TO-SEVERE RHEUMATOID ARTHRITIS WITH 3 YEARS OF TREATMENT: RESULTS FROM A LONG-TERM STUDY}

J. S. Smolen ${ }^{1}$, L. Xie ${ }^{2}$, B. Jia ${ }^{2}$, P. C. Taylor ${ }^{3}$, G. R. Burmester ${ }^{4}$, Y. Tanaka ${ }^{5}$, A. Elias ${ }^{2}$, A. Cardoso ${ }^{2}$, R. Ortmann ${ }^{2}$, C. Walls ${ }^{2}$, M. Dougados ${ }^{6} .{ }^{1}$ Medical University of Vienna, Division of Rheumatology, Vienna, Austria; ${ }^{2}$ Eli Lilly and Company, Indianapolis, United States of America; ${ }^{3}$ University of Oxford, Oxford, United Kingdom; ${ }^{4}$ Charité - University Medicine Berlin, Berlin, Germany; ${ }^{5}$ University of Occupational and Environmental Health, Japan, Kitakyushu, Japan; ${ }^{6}$ Hospital Cochin Paris, Paris, France

Background: Baricitinib (Bari) is an oral, selective and reversible Janus kinase and 2 inhibitor approved for the treatment of adults with active RA. In addition to long-term safety which has been disclosed previously with data up to 7 years [1] an important clinical consideration is whether treatment efficacy can be maintained over the long term.

Objectives: To evaluate the long-term efficacy of once-daily Bari $4 \mathrm{mg}$ in patients with active rheumatoid arthritis $(R A)$ who were either naïve to or who had inadequate response (IR) to methotrexate (MTX)

Methods: Post hoc analyses of data from two phase 3 studies, RA-BEGIN (MTX-naïve) and RA-BEAM (MTX-IR) for 52 weeks, and one long-term extension (LTE) study (RA-BEYOND) for an additional 96 weeks were conducted (148 weeks in total). At week 52, MTX-naïve patients initially treated with MTX monotherapy, Bari $4 \mathrm{mg}$ monotherapy, or Bari $4 \mathrm{mg}+\mathrm{MTX}$ in RA-BEGIN were switched to open-label Bari $4 \mathrm{mg}$ monotherapy for treatment in the LTE. Similarly, at week 52, MTX-IR patients initially treated with Bari $4 \mathrm{mg}$ [+ background MTX noted as (+MTX) for RA-BEAM] or adalimumab (ADA) (+MTX) in RA-BEAM were switched to open-label Bari $4 \mathrm{mg}(+\mathrm{MTX})$ for treatment in the LTE. Patients who received placebo $(+\mathrm{MTX})$ were switched to open-label Bari $4 \mathrm{mg}(+\mathrm{MTX})$ at week 24. The analyses of efficacy (SDAI) and physical function (HAQ-DI) were conducted on all patients who were randomized into the RA-BEGIN and RA-BEAM studies and had received $\geq 1$ dose of study drug after randomization (mITT population). The proportion of patients who reached low disease activity (LDA), as measured by SDAI $\leq 11$, was evaluated along with change from baseline in HAQ-DI. The non-responder imputation (NRI) method was used for the categorical analysis.

Results: By week 24 in RA-BEGIN (N=584), $62 \%$ of patients treated with Bari $4 \mathrm{mg}$ monotherapy or Bari $4 \mathrm{mg}+\mathrm{MTX}$ achieved SDAI LDA in comparison to $40 \%$ of pts in the MTX monotherapy group; response rates seen at week 24 in the Bari treatment groups were maintained through week 148 (Fig 1A). Similarly, by week 24 in RA-BEAM $(\mathrm{N}=1,305), 52 \%$ of patients treated with Bari $4 \mathrm{mg}(+\mathrm{MTX})$ and $50 \%$ of patients treated with ADA (+MTX) achieved a SDAI LDA in comparison to $26 \%$ of patients from the PBO (+MTX) group. The response rate seen at week 24 with Bari $4 \mathrm{mg}$ and ADA were maintained through week 148, even after patients switched from ADA to Bari $4 \mathrm{mg}$ at week 52 (Fig 1B). Similar improvement and maintenance patterns in physical function measured by HAQ-DI were demonstrated. The overall discontinuation rate across treatment groups from RA-BEGIN (19.5\%) and RA-BEAM (14.2\%) have been published. In the LTE, the discontinuation rate from Bari treatment was $13.7 \%$ for patients originating from RA-BEGIN (1.1\% due to lack of efficacy, $6.4 \%$ due to safety) and $12.6 \%$ for patients originating from RA-BEAM ( $1.8 \%$ due to lack of efficacy, $5.9 \%$ due to safety).
A. RA-BEGIN ${ }^{\dagger \S}$

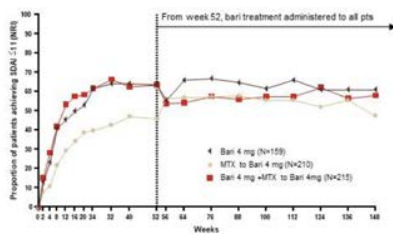

B. RA-BEAM ${ }^{\ddagger \S}$

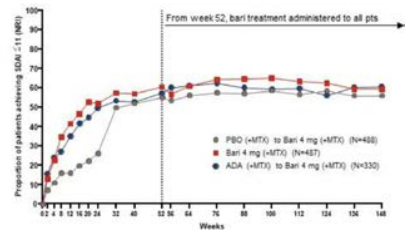

Figure 1. Proportion of patients achieving SDAI $\leq 11$ in the NRI analysis ${ }^{\dagger}$ In RA-BEGIN, rescue to Bari $4 \mathrm{mg}+$ MTX was offered at week $24{ }^{\ddagger}$ In RA-BEAM, rescue to Bari $4 \mathrm{mg}$ (+ MTX) was offered at week 16. At week 24, all PBO + MTX patients were switched to Bari $4 \mathrm{mg}+\mathrm{MTX}$. ${ }^{\S}$ Upon entering RA-BEYOND at week 52, MTX and ADA patients were switched to Bari $4 \mathrm{mg}$.

Conclusion: Long-term treatment with Bari $4 \mathrm{mg}$ demonstrated the maintenance of clinically-relevant outcomes for up to 3 years. Low discontinuation rates during the LTE indicated that Bari $4 \mathrm{mg}$ treatment was well-tolerated.
References:

[1] Genovese et al. Annals of the Rheumatic Diseases. 2019;78:308-309.

Disclosure of Interests: : Josef S. Smolen Grant/research support from: AbbVie AstraZeneca, Celgene, Celltrion, Chugai, Eli Lilly, Gilead, ILTOO, Janssen, Novartis-Sandoz, Pfizer Inc, Samsung, Sanofi, Consultant of: AbbVie, AstraZeneca, Celgene, Celltrion, Chugai, Eli Lilly, Gilead, ILTOO, Janssen, Novartis-Sandoz, Pfizer Inc, Samsung, Sanofi, Li Xie Shareholder of: Eli Lilly and Company, Employee of: Eli Lilly and Company, Bochao Jia Shareholder of: Eli Lilly and Company, Employee of: Eli Lilly and Company, Peter C. Taylor Grant/research support from: Celgene Eli Lilly and Company, Galapagos, and Gilead, Consultant of: AbbVie, Biogen, Eli Lilly and Company, Fresenius, Galapagos, Gilead, GlaxoSmithKline, Janssen, Nordic Pharma, Pfizer Roche, and UCB, Gerd Rüdiger Burmester Consultant of: AbbVie Inc, Eli Lilly, Gilead, Janssen, Merck, Roche, Pfizer, and UCB Pharma, Speakers bureau: AbbVie Inc, Eli Lilly, Gilead, Janssen, Merck, Roche, Pfizer, and UCB Pharma, Yoshiya Tanaka Grant/research support from: Asahi-kasei, Astellas, Mitsubishi-Tanabe, Chugai, Takeda, Sanofi, Bristol-Myers, UCB, Daiichi-Sankyo Eisai, Pfizer, and Ono, Consultant of: Abbvie, Astellas, Bristol-Myers Squibb, El Lilly, Pfizer, Speakers bureau: Daiichi-Sankyo, Astellas, Chugai, Eli Lilly, Pfizer AbbVie, YL Biologics, Bristol-Myers, Takeda, Mitsubishi-Tanabe, Novartis, Eisai, Janssen, Sanofi, UCB, and Teijin, Ayesha Elias Shareholder of: Eli Lilly and Company, Employee of: Eli Lilly and Company, Anabela Cardoso Shareholder of: Eli Lilly and Company, Employee of: Eli Lilly and Company, Robert Ortmann Shareholder of: Eli Lilly and Company, Employee of: Eli Lilly and Company, Chad Walls Shareholder of: Eli Lilly and Company, Employee of: Eli Lilly and Company, Maxime Dougados Grant/research support from: AbbVie, Eli Lilly, Merck, Novartis, Pfizer and UCB Pharma, Consultant of: AbbVie, Eli Lilly, Merck, Novartis, Pfizer and UCB Pharma, Speakers bureau: AbbVie, Eli Lilly, Merck, Novartis, Pfizer and UCB Pharma

DOI: 10.1136/annrheumdis-2020-eular.2398

\section{SAT0153 \\ GENDER DOES NOT INFLUENCE CLINICAL RESPONSE TO JAK INHIBITORS IN RHEUMATOID ARTHRITIS: AN ITALIAN MULTICENTRE ANALYSIS}

F. R. Spinelli ${ }^{1}$, M. S. Chimenti ${ }^{2}$, M. Vadacca ${ }^{3}$, C. Iannuccelli ${ }^{1}$, P. Conigliaro ${ }^{2}$ S. L. Bosello ${ }^{4}$, F. Ceccarelli ${ }^{1}$, C. Garufi ${ }^{1}$, G. Raffone ${ }^{2}$, P. Di Noi ${ }^{3}$, D. Bruno ${ }^{5}$, A. Afeltra ${ }^{3}$, R. Perricone ${ }^{2}$, F. Conti $^{6}$, E. Gremese ${ }^{4,5}$ on behalf of FRS, MSC, PC, $\mathrm{MV}, \mathrm{CI}, \mathrm{SLB}$ and EG on behalf of ReDO - Reumatologhe Donne - association of italian female rheumatologists.. ' Sapienza Università di Roma, Rheumatology Unit, 00161, Italy; ${ }^{2}$ University of Rome Tor Vergata, Rheumatology, Allergology and Clinical Immunology, Rome, Italy; ${ }^{3}$ Campus Biomedico University of Rome, Rheumatology, Allergology and Clinical Immunology, Rome, Italy; ${ }^{4}$ Fondazione Policlinico Universitario A. Gemelli IRCCS, Rheumatology Division, Rome, Italy; ${ }^{5}$ Università Cattolica del Sacro Cuore, Rheumatology Division, Rome, Italy;

${ }^{6}$ Sapienza Università di Roma, Rheumatology Unit, Rome, Italy

Background: Gender medicine aims at describing how diseases differ between men and women in terms of epidemiology, clinical feature, therapeutic approach, treatment response and prognosis, psychological and social impact. Rheumatoid Arthritis (RA) affects women 2-3 times more than men. Female gender seems to be independently associated to a more refractory disease and a worst response to conventional synthetic Disease Modifying Anti-Rheumatic Drugs (csDMARDs) and biological DMARDs. Male patients achieve remission more often than females probably due to the higher number of tender joints reported by the latter.

Objectives: In the light of the effect of Janus kinases inhibitors (JAKi) on pain, the objective of the study was to investigate whether gender might affect the achievement of remission or low disease activity in RA patients treated with baricitinib and tofacitinib.

Methods: We performed a multicentric, prospective study on consecutive patients starting one of the two available JAKi: baricitinib and tofacitinib. Demographic and clinical data were recorded in a dedicate database and included: gender, age, disease duration, serological status (Rheumatoid Factor - RF; anti-citrullinated peptide antibodies, ACPA) number of previous csDMARDs and bDMARDs, number of tender joints (TJ) and swollen joints (SJ), $C$ reactive protein (CRP); patient global assessment (PGA) and pain were recorded on a $0-100 \mathrm{~mm}$ visual-analogue scale (VAS). Disease activity score (DAS) 28 was calculated at baseline and at two follow-up visits (after 3-4 months and after 6-8 months). Data were expressed as mean \pm standard deviation or median (interquartile range) according to variables' distribution. Continuous variables were compared by Mann Whitney test while dichotomous ones by Chi-squared test; $p$ value $<0.05$ were considered statistically significant.

Results: We enrolled 182 RA patients (149 F:33M) with similar age (F 58 \pm 12 vs $M \quad 60 \pm 10$ ) and disease duration (F 143 \pm 101 vs M 147 \pm 105 months). Females and males were previously treated with the same number of csDMARDs [2(2)] but female have previously received numerically more bDMARDs [2(3) vs 1(2)] At the 3 timepoints females and males showed similar number of TJ, SJ, similar values of CRP, PGA and pain. We did not observe any difference in percentage 
of males and females achieving remission or low disease activity according to gender (figure 1A) nor in terms of reduction of TJ, SJ and PGA; only pain decreased significantly more in male than in female patients at both timepoints (figure 1B).

Conclusion: In RA patients treated with JAK inhibitors, even if the effect of JAKi on pain seems to be more relevant in male than in female, gender seems not to influence the overall clinical response, allowing men and women the same probability of reaching the therapeutic target

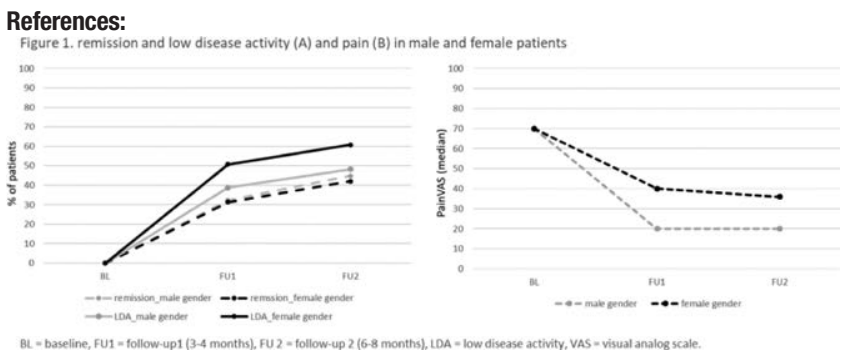

Disclosure of Interests: Francesca Romana Spinelli Grant/research support from: Pfizer, Speakers bureau: Lilly, BMS, Celgene, Maria Sole Chimenti: None declared, Marta Vadacca: None declared, Cristina lannuccelli: None declared, Paola Conigliaro: None declared, Silvia Laura Bosello: None declared, Fulvia Ceccarelli: None declared, Cristina Garufi: None declared, Giulia Raffone: None declared, Paola Di Noi: None declared, Dario Bruno: None declared, Antonella Afeltra: None declared, Roberto Perricone: None declared, fabrizio conti Speakers bureau: BMS, Lilly, Abbvie, Pfizer, Sanofi, Elisa Gremese Speakers bureau: Abbvie, BMS, Celgene, Jannsen, Lilly, MSD, Novartis, Pfizer, Sandoz, UCB DOI: 10.1136/annrheumdis-2020-eular.5978

\section{SAT0154 \\ EXAMINATION OF CYP3A5 GENOTYPE IS USEFUL FOR INTRODUCTION OF TACROLIMUS TREATMENT IN OUTPATIENTS WITH RHEUMATIC DISEASES}

S. Takahashi ${ }^{1}, 2$, S. Horibata ${ }^{2,3}$, S. Hatachi ${ }^{1}$, M. Takahashi $^{2}$, M. Katayama ${ }^{1}$, S. Mukohara ${ }^{1}$, N. Amano ${ }^{1}$, K. Yoshida ${ }^{1}$, K. Yorifuji ${ }^{2,3}$, S. Kumagai ${ }^{1,2} .{ }^{1}$ Center for Rheumatic Disease, Shinko Hospital, Kobe, Japan; ${ }^{2}$ Shinko Institute for Medical Research, Kobe, Japan; ${ }^{3}$ Department of Pharmacy, Shinko Hospital, Kobe, Japan

Background: Though several studies showed the efficacy of tacrolimus (TAC) in patients with rheumatoid arthritis (RA) in a dose-depending manner [1], the relationship between efficacy and concentration of TAC remained unclear. Genetic polymorphisms of cytochrome P450 (CYP) 3A5 were reported not only to play an important role in pharmacokinetics of TAC but also to have an influence on clinical outcomes in patients of rheumatic diseases. Several reports showed that the blood concentration of TAC in patients with a CYP3A5 *1 allele (EX, expressor) was lower than that of patients with a CYP3A5 ${ }^{*} 3{ }^{*} 3($ NEX, non-expressor) [2]

Objectives: To assess the relationship between efficacy and concentration of TAC in patients with RA, and to examine the usefulness of CYP3A5 genotype screening to detect outpatients suitable for TAC treatment.

Methods: We examined the relationship between disease activity score (DAS) 28-CRP and concentration of TAC in patients with RA. TAC was taken after the evening meal and blood samples were taken $12 \pm 4 \mathrm{~h}$ after TAC administration. Next we investigated the relationship between genotype frequencies of CYP3A5 and concentration of TAC in patients with rheumatic disease without having renal dysfunction (eGFR<60) and also investigated the influence of concomitant drugs, such as strong inhibitors of CYP3A4/5 or metabolized by CYP3A4/5, to C/D value in each NEX and EX group. The blood concentration of TAC normalized to the corresponding dose per body weight (C/D, ng/ $\mathrm{ml}$ per $\mathrm{mg} / \mathrm{kg}$ ) was analyzed according to genetic variation in CYP3A5. Furthermore we investigated the relationship between genotype frequencies of CYP3A5 and concentration of TAC in patients with rheumatic disease at first visit and second visit after starting TAC administration to assess the possibility for making rapid attainment of enough concentrations of TAC in early stage of treatment.

Results: The concentration of TAC tended to be negatively correlated with the disease activity of RA. The C/D value in the NEX group $(n=16)$ was $124.7 \pm 62.1$, which was significantly higher than that in the EX group $(n=23 ; 67.7 \pm 29.8 ; P<0.001)$. When comparing patients using concomitant drugs which are strong inhibitors of CYP3A4/5 or metabolized by CYP3A $4 / 5$ with patients not using those drugs, the each C/D value of NEX group was
$122.9 \pm 52.3(n=9)$ and $126.9 \pm 77.3(n=7)$, and that of EX group was $71.3 \pm 32.2$ $(n=12)$ and $63.8 \pm 28.0(n=11)$. There were no significant differences between these groups. In NEX group, when comparing concentration of TAC at first visit and second visit after starting TAC administration, the each concentration of TAC was $3.14 \pm 2.06 \mathrm{ng} / \mathrm{ml}$ and $3.80 \pm 2.20 \mathrm{ng} / \mathrm{ml}$ in NEX group $(n=10)$, and that of TAC was $1.82 \pm 0.82 \mathrm{ng} / \mathrm{ml}$ and $2.69 \pm 1.52 \mathrm{ng} / \mathrm{ml}(\mathrm{n}=11)$ in $E X$ group (Figure).

Conclusion: TAC showed efficacy in patients with RA in a concentration-dependent manner. EX patients may be impossible to achieve enough concentration of TAC even though using TAC of $3 \mathrm{mg} /$ day, approved dose for patients with RA in Japan, and NEX patients could make rapid attainment of enough concentrations of TAC in early stage of treatment, suggesting that we should consider induction of TAC only in NEX outpatients. Furthermore, drugs only slightly affected concentration of TAC in this study, suggesting that we can use TAC without any special attention to concomitant drugs.

References:

[1] Furst DE et al. Arthritis Rheum 2002;46:2020-28

[2] Y. Muraki et al. Exp Ther Med 2018;15:532-38.

\section{NEX patients rapidly gain higher TAC concentration than EX patients in early stage of treatment}

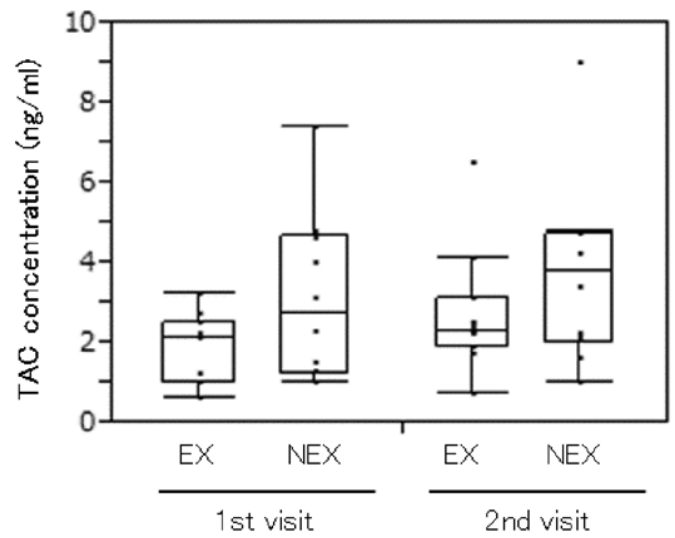

Acknowledgments: none

Disclosure of Interests: Soshi Takahashi: None declared, Shinji Horibata: None declared, Saori Hatachi: None declared, Miho Takahashi: None declared, Motoko Katayama: None declared, Saki Mukohara: None declared, Norihiko Amano: None declared, Katsuyuki Yoshida: None declared, Kennosuke Yorifuji: None declared, Shunichi Kumagai Grant/research support from: Astellas, Chugai, Mitsubishi Tanabe Co.Ltds, Consultant of: Sysmex Co.Ltd, Speakers bureau: many companies

DOI: 10.1136/annrheumdis-2020-eular.4028

\begin{tabular}{|l|l}
\hline SAT0155 & WHOLE BLOOD TRANSCRIPTIONAL CHANGES \\
& FOLLOWING SELECTIVE INHIBITION OF JANUS \\
& KINASE 1 (JAK1) BY FILGOTINIB IN MTX-NAÏVE \\
& ADULTS WITH MODERATELY-TO-SEVERELY ACTIVE \\
& RHEUMATOID ARTHRITIS (RA) (FINCH3)
\end{tabular}

P. C. Taylor' ${ }^{1}$, B. Downie' ${ }^{2}$, E. Elboudwarej' ${ }^{2}$ S. Kim², A. Hertz², A. M. Mirza², J. Siegel ${ }^{2}$, R. E. Hawtin ${ }^{2}$, J. Liu' ${ }^{2}{ }^{1}$ University of Oxford, Botnar Research Centre, Nuffield Dept Orthopaedics, Rheumatology and Musculoskeletal Sciences, Oxford, United Kingdom; ${ }^{2}$ Gilead Sciences Inc., Foster City, United States of America

Background: Filgotinib (FIL), an oral selective JAK1 inhibitor, has shown efficacy and safety in multiple phase 3 studies in adults with moderately-to-severely active rheumatoid arthritis (RA). We have previously described the molecular response to FIL in large-scale RNA sequencing studies of gene expression in other RA populations ${ }^{1-3}$ and conducted a similar study in methotrexate (MTX)-naïve RA patients (pts) (FINCH3).

Objectives: Identify gene transcripts and biological pathways associated with RA and those altered in response to FIL treatment.

Methods: MTX-naïve RA pts who were enrolled in FINCH3 (ClinicalTrials.gov NCT02886728) received a stable dose of MTX with placebo (PBO+MTX), FIL $200 \mathrm{mg}$ alone (FIL 200mg monotherapy), or one of two doses of FIL once daily (QD) together with MTX (FIL 100mg+MTX, FIL 200mg+MTX). Whole blood samples were collected from pts using PAXgene tubes at baseline, week 4, 